\title{
Some Common Fixed Point Results for Expansive Mappings in a Cone Metric Space
}

\author{
S.K. Tiwari*1 ${ }^{1}$, R. P. Dubey ${ }^{1}$, A. K. Dubey ${ }^{2}$ \\ ${ }^{I}$ Department of Mathematics, Dr. C.V. Raman University, Bilaspur, Chhattisgarh, India-495113 \\ ${ }^{2}$ Department of Mathmetics, Bhilai Institute of Technology Bhilai House, Durg India 491001
}

\begin{abstract}
The purpose of this work is to extend and generalize some common fixed point theorems for Expansive type mappings in complete cone metric spaces. We are attempting to generalize the several wellknown recent results.
\end{abstract}

Mathematical subject classification; 54H25, 47H10

Key word: Complete cone metric space, common fixed point, expansive type mapping.

\section{Introduction}

Very recently, Huang and Zhang [3] introduced the concept of cone metric space by replacing the set of real numbers by an ordered Banach space. They prove some fixed point Theorems for contractive mappings using normality of the cone. The results in [3] were generalized by Sh. Rezapour and Hamlbarani [4] omitted the assumption of normality on the cone, which is a milestone in cone metric space.

In this manuscript, the known results [14] are extended to cone metric spaces where the existence of common fixed points for expansive type mappings on cone metric spaces is investigated.

\section{Preliminary Notes}

Definition 2.1[3] : Let $E$ be a real Banach space and $P$, a subset of $E$. Then $P$ is called a cone if and only if:

(i) $\mathrm{P}$ is closed, non-empty and $\mathrm{P} \neq\{0\}$;

(ii) $a, b \in R, a, b \geq 0 x, y \in \boldsymbol{P} \Rightarrow a x+b y \in \boldsymbol{P}$;

(iii) $x \in \mathrm{P}$ and $-x \in \mathrm{P} \Rightarrow x=0$.

Given a cone $\mathrm{P} \subseteq \mathrm{E}$, we define a Partial ordering $\leq$ on $\mathrm{E}$ with respect to $\mathrm{P}$ by $x \leq y$ if and only if $y-x \in \boldsymbol{P}$. We shall write $\mathrm{x} \ll \mathrm{y}$ to denote $x \leq y$ but $x \neq y$ to denote $y-x \in \mathrm{p}^{0}$, where $p^{0}$ stands for the interior of $\mathrm{P}$.

Remark 2.2 [7]: $\lambda p^{0} \subseteq p^{0}$ for $\lambda>0$ and $p^{0}+p^{0} \subseteq p^{0}$

Definition 2.2 [3] : Let $X$ be a non-empty set and $d: X \times X \rightarrow E$ a mapping such that $\left(d_{1}\right) 0 \leq(x, y)$ for all $x, y \in X$ and $d(x, y)=0$ if and only if $x=y$,

$\left(d_{2}\right) d(x, y)=d(y, x)$ for all $x, y \in X$,

$\left(d_{3}\right) d(x, y) \leq d(x, z)+d(z, y)$ for all $x, y, z \in X$.

Then $\mathrm{d}$ is called a cone metric on $X$, and $(X, \mathrm{~d})$ is called a cone metric space.

Example 2.4 [3]: Let $E=R^{2}, P\{(x, y) \in E: x, y \geq 0\}$ and $X=Y$, defined by $d(x, y)=(\alpha|x-y|$, $\beta|x-y|, \gamma \mid x-y)$ where $\alpha, \beta, \gamma \geq 0$ is a constant. Then $(X, d)$ is a cone metric space.

Definition 2.5 [3]: Let $(X, d)$ be a cone metric space, $x \in X$ and $\left\{x_{n}\right\}$ be a sequence in $X$. Then

(i) $\left\{x_{n}\right\}_{n \geq 1}$ converges to $x$ whenever to every $c \in E$ with $0 \ll c$ there is a natural number $\mathrm{N}$ such that $d\left(x_{n}, x\right) \ll c$ for all $\mathrm{n} \geq \mathrm{N}$.

(ii) $\left\{x_{n}\right\}_{n \geq 1}$ is said to be a Cauchy sequence if for every $c \in E$ with $0 \ll c$ there is a natural number $\mathrm{N}$ such that $d\left(x_{n}, x_{m}\right) \geq c$ for all $n, m \geq N$.

(iii) $(X, d)$ is called a complete cone metric space if every Cauchy sequence in $X$ is convergent in $X$.

Definition 2.6[3]: Let $(X, d)$ be a cone metric space, $P$ be a cone in real Banach space $E$, if

(i) $a \in \mathrm{P}$ and $a \ll c$ for some $k \epsilon[0,1]$ then $a=0$.

(ii) $a \in \mathrm{P}$ and $a \ll c$ for some $k \epsilon[0,1]$ then $a=0$.

(iii) $u \leq v, v \ll w$, then $u \ll w$. 


\section{Lemma 2.7}

Let $(x, d)$ be a cone metric space and $P$ be a cone metric space in real Banach space $E$ and $\alpha_{1}, \alpha_{2}, \alpha_{3} . \alpha_{4} \alpha \geq 0$. If $x_{n} \rightarrow x, y_{n} \rightarrow y, z_{n} \rightarrow \mathrm{z}$, and

$\mathrm{a}_{\mathrm{n}} \rightarrow p$ in $x$ and $\alpha_{1} d\left(x_{n}, x\right),+\alpha_{2} d\left(y_{n}, y\right)+\alpha_{3} d\left(z_{n}, z\right)+\alpha_{4} d\left(p_{n}, p\right)$.Then $a=0$.

\section{Main Reault:}

Theorem 3.1 Let $(X, d)$ be a complete cone metric space with respect to a cone $\mathrm{P}$ containing in a real Banach space $E$. Let $\mathrm{R}_{1}, \mathrm{R}_{2}$ be any two surjective self mappings of $X$ satisfy $\boldsymbol{d}\left(R_{1} x, R_{2} \mathrm{y}\right) \geq \alpha d\left(x, R_{1} x\right)+\beta d\left(y, R_{2} y\right)+\gamma d(x, y)+k\left[d\left(x, R_{2} y\right)+d\left(y, R_{1} x\right)\right] \ldots \ldots(3.1 .1)$ for each $x, y \in X, x \neq y$ where $\alpha, \beta, \gamma, k \geq 0, \alpha+\beta+\gamma>1+2 k, \beta+\gamma>\mathrm{k}$ and $\gamma>2 \mathrm{k}$. Then $R_{1}$ and $R_{2}$ have a unique common fixed point.

Proof: Let $\mathrm{x}_{0}$ be an arbitrary point in X. Since $\mathrm{R}_{1}$ and $\mathrm{R}_{2}$ surjective mappings, there exist points $x_{1} \in R_{1}^{-1}\left(x_{0}\right)$ and $x_{2} \in R_{2}^{-1}\left(x_{1}\right)$ that is $R_{1}\left(x_{1}\right)=x_{0}$ and $R_{2}\left(x_{2}\right)=x_{1}$. In this way, we define the sequence $\left\{x_{n}\right\}$ with $x_{2 n+1} \in R_{1}^{-1}\left(x_{2 n}\right)$ and $x_{2 n+2} \in R_{2}^{-1}\left(x_{2 n+1}\right)$.

i.e. $x_{2 n}=R_{1} x_{2 n+1}$ for $\mathrm{n}=0,1,2$,

$$
x_{2 n+1}=R_{2} x_{2 n+2} \text { for } \mathrm{n}=0,1,2 \text {. }
$$

Note that, if $x_{2 n}=x_{2 n+1}$ for some $\mathrm{n} \geq 0$, then $x_{2 n}$ is fixed point of $R_{1}$ and $R_{2}$. Now putting $\mathrm{x}=x_{2 n+1}$ and $y=x_{2 n+2}$ from (3.1.1), we have

$$
\begin{aligned}
& d\left(R_{1} x_{2 n+1}, R_{2} x_{2 n+2}\right)=\alpha d\left(x_{2 n+1}, R_{1} x_{2 n+1}\right)+\beta d\left(x_{2 n+2}, R_{2} x_{2 n+2}\right)+\gamma d\left(x_{2 n+1}, x_{2 n+2}\right) \\
& +k\left[d\left(x_{2 n+1}, R_{2} x_{2 n+2}\right)+d\left(x_{2 n+2}, R_{2} x_{2 n+1}\right)\right] \\
& \Rightarrow d\left(x_{2 n}, x_{2 n+1}\right) \geq \alpha d\left(x_{2 n+1}, x_{2 n}\right)+\beta d\left(x_{2 n+2,} x_{2 n+1}\right)+\gamma d\left(x_{2 n+1}, x_{2 n+2}\right) \\
& +k\left[d\left(x_{2 n+1}, x_{2 n+1}\right)+d\left(x_{2 n+2}, x_{2 n}\right)\right] \\
& \Rightarrow d\left(x_{2 n}, x_{2 n+1}\right) \geq \alpha d\left(x_{2 n+1}, x_{2 n}\right)+\beta d\left(x_{2 n+2}, x_{2 n+1}\right)+\gamma d\left(x_{2 n+1}, x_{2 n+2}\right) \\
& +k\left[d\left(x_{2 n+2}, x_{2 n+1}\right)+d\left(x_{2 n+1}, x_{2 n}\right)\right] \\
& \Rightarrow d\left(x_{2 n}, x_{2 n+1}\right) \geq[\alpha+k] d\left(x_{2 n+1}, x_{2 n}\right)+[\beta+\gamma+k] d\left(x_{2 n+1}, x_{2 n+2}\right) \\
& \Rightarrow d\left(x_{2 n+1}, x_{2 n+2}\right) \leq \frac{1-(\alpha+k)}{\beta+\gamma+k}\left(x_{2 n}, x_{2 n+1}\right) \\
& d\left(x_{2 n}, x_{2 n+1}\right) \leq h d\left(x_{2 n-1}, x_{2 n}\right) \\
& \Rightarrow d\left(x_{2 n}, x_{2 n+1}\right) \leq h^{2 n}\left(x_{2 n-1}, x_{2 n}\right)
\end{aligned}
$$

So for every positive integer $\mathrm{p}$, we have

$$
\begin{aligned}
d\left(x_{2 n}, x_{2 n+p}\right) \leq d & \left(x_{2 n}, x_{2 n+1}\right)+d\left(x_{2 n+1} x_{2 n+2}\right)+\ldots \ldots \ldots+d\left(x_{2 n+p-1}, x_{2 n+p}\right) \\
& \leq\left(h^{2 n}+h^{2 n+1}+\ldots \ldots \ldots \ldots+h^{2 n+p-1}\right) d\left(x_{0}, x_{1}\right) \\
& =h^{2 n}\left(1+h+h^{2}+\ldots \ldots \ldots \ldots+h^{2 n+p-1}\right) d\left(x_{0}, x_{1}\right) \\
& <\frac{h^{2 n}}{1-h} \mathrm{~d}\left(x_{0}, x_{1}\right) \ldots \ldots \ldots \ldots \ldots \ldots \ldots \ldots . . .6 \ldots \ldots \ldots \ldots \ldots
\end{aligned}
$$

Therefore $\left\{x_{2 n}\right\}$ is a Cauchy sequence, which is complete space in $\mathrm{X}$ there exist $x^{*} \in X$ such that $x_{2 n \rightarrow} x^{*}$. Since $\mathrm{R}_{1}$ is surjective map, there exist a point $\mathrm{y}$ in $\mathrm{X}$ such that

$$
\begin{aligned}
& y \in R_{1}^{-1}\left(x^{*}\right) \text {. i.e. } x^{*}=R_{1}(y) \\
& \text { Now consider } d\left(x_{2 n, x^{*}}\right)=d\left(R_{1} x_{2 n+1}, y\right) \\
& \geq \alpha d\left(x_{2 n+1}, R_{1} x_{2 n+1}\right)+\beta d\left(y, R_{1} y\right)+\gamma d\left(x_{2 n+1}, y\right)+k\left[d\left(x_{2 n+1}, R_{1} y\right)+\right. \\
& \Rightarrow d\left(x^{*}, x^{*}\right) \geq \alpha d\left(x^{*}, x^{*}\right)+\beta d\left(y, x^{*}\right)+\gamma d\left(x^{*}, y\right)+ \\
& k\left[d\left(x_{2 n+1}, R_{1} y\right)+d\left(y, R_{1} x_{2 n+1}\right)\right] \\
& \Rightarrow d\left(x^{*}, x^{*}\right) \geq \alpha d\left(x^{*}, x^{*}\right)+\beta d\left(y, x^{*}\right)+\gamma d\left(x^{*}, y\right)+k\left[d\left(x_{2 n+1}, R_{1} y\right)+d\left(y, R_{1} x_{2 n+1}\right)\right] \\
& \Rightarrow \quad 0 \geq(\beta+\gamma+k) \mathrm{d}\left(x^{*}, y\right) \\
& \Rightarrow d\left(x^{*} y\right) \quad=0, \text { as }(\beta+\gamma+k)>0 \\
& \Rightarrow x^{*}=\mathrm{y}
\end{aligned}
$$

Hence $x^{*}$ is a fixed point of $R_{1}$ as $R_{1} y=x^{*}=y$. Now if $\mathrm{z}$ be another fixed point of $R_{1}$, i.e. $\mathrm{R}_{1} \mathrm{z}=\mathrm{z}$. Then $\left(x^{*}, \mathrm{z}\right)=d\left(R_{1} x^{*}, R_{1} \mathrm{z}\right)$

$$
\begin{aligned}
& \geq \alpha d\left(R_{1} x^{*}, R_{1} z\right)+\beta d\left(z, R_{1} \mathrm{z}\right)+\gamma d\left(x^{*}, z\right)+k\left[d\left(x^{*}, z\right)+\mathrm{d}\left(\mathrm{z}, x^{*}\right)\right] \\
& \quad=\mathrm{k}\left[d\left(x^{*}, z\right)+\left(z, x^{*}\right)\right]+\gamma d\left(x^{*}, z\right)\left(\mathrm{z}, R_{1} z\right) \\
& =(2 k+\gamma) d\left(x^{*}, \mathrm{z}\right)
\end{aligned}
$$


$\Rightarrow d\left(x^{*}, z\right) \leq \frac{1}{c+2 k} d\left(x^{*}, z\right)$

$\Rightarrow d\left(x^{*}, z\right)=0$ as $c>2 k$ as and by proposition 2.6 (i).

$\Rightarrow x^{*}=z$. Therefore $R_{1}$ has a unique fixed point .Similarly it can be established that $R_{2} x^{*}=x^{*}$. Hence $R_{1} x^{*}$

$=x^{*}=R_{2} x^{*}$. Thus $x^{*}$ is the common fixed point of $R_{1}$ and $R_{2}$. These completed the proof of the theorem.

Corollary 3.2 Let $(\mathrm{x}, \mathrm{d})$ be a complete cone metric space with respect to a cone $\mathrm{P}$ containing in a real Banach space $E$. Let $\mathrm{R}_{1}$ and $\mathrm{R}_{2}$ be any two surjective self mappings of $X$ satisfying

$d\left(R_{1} x, R_{2} \mathrm{y}\right) \geq \alpha d\left(\mathrm{x}, R_{1} x\right)+\beta d\left(\mathrm{y}, R_{2} \mathrm{y}\right)+\gamma d(x, y) \ldots \ldots . .(3.1 .9)$

For each $, \epsilon X, x \neq y$ where $\alpha, \beta, \gamma, \geq 0, \alpha+\beta+\gamma>1$. Then $R_{1}$ and $R_{2}$ have a unique fixed point.

Proof: The proof of the corollary immediately follows by putting $k=0$ in the previous theorem.

Corollary 3.3 Let $(\mathrm{x}, \mathrm{d})$ be a complete cone metric space with respect to a cone $\mathrm{p}$ containing in a real Banach space $E$. Let $\mathrm{R}_{1}$ and $\mathrm{R}_{2}$ be any two surjective self mappings of $X$ satisfying $d\left(R_{1} x, R_{2} y\right) \geq k\left[d\left(x, R_{2} y\right)+d\left(y, R_{1} x\right)\right]$ For each $x, \epsilon X, x \neq y$ where $k \geq 0$

Then $R_{1}$ and $R_{2}$ have a unique fixed point.

Proof: The proof of the corollary immediately follows by putting $\alpha=0, \beta=0$ and $\gamma=0$ in the previous theorem.

\section{References}

[1] D.Jlic and V.Rakocevic, Quasi-Contraction on a cone metric space, Appl.Lett., 22,(5),(2009),728-731.

[2] D. Turkoglu and M .Abuloha and Tt .Abdeljawad, KKM mapping in cone metric spaces and some fixed point theorems, Nonlinear Analysis Theory ,Methods and Applications, 72 (2010) 348-353,

[3] Huang Long - Guang, Zhang Xian, Cone metric spaces and Fixed Point Theorems of Contractive mappings. J.math.Anal.Appl.332 (2007)1468-1476

[4] Sh. Rezapour, R. Hamal barani, some notes on the paper "Cone metric spaces and Fixed Point Theorems of Contractive mappings. J.math.Anal.Appl.345 (2), (2008) 719-724.

[5] J.O.Olaleru, some generalizations of fixed point theorems in cone metric spaces, Fixed point theory and Apllications (2009), Article ID 65791

[6] C.T. AAGE \& J.N. Salunke, On common Fixed Points for Contractive Type Mapping in cone metric spaces. Bulletin of Mathematical Analysis and application. 13 (2009) 10-13.

[7] G.E Hardy. \& T. D Rogers., A generalization of fixed point theorem of Reich canad, math. Bull. 16, (1973) 201-206.

[8] I. Sahin and M. Telci, Fixed point of contractive mappings on complete cone metric spaces, Hcettepe journal of mathematicsa and stastics, 38 , (2009) 59-67.

[9] Shobha jain, Shishir jain,Lal bahadur, compatibility and weak compatibility for four self maps in a cone metric space.Bulletin of Mathematical Analysis and Application 2,1,(2010) 15-24.

[10] Erdal Karapinar Fixed point Theorems in cone Banach space, fixed point theory and Applications Vol 2009 ,Article ID 609281.

[11] V. Raj and S.M. Veazpour, Some extention of Banach Contraction Principle in complete cone metric spaces, Fixed Point Theory and Applications, (2008) 11P.

[12] F. E. Browder, W.V. Petryshyn, The solution by iteration of nonlinear functional equations in Banach spaces. Bull. Amer Math. Soc., 72, (1966) 571-575

[13] Tjabet Abdeljawad Erdal Karapinar quasi cone metric spaces and generalization of Caristi Kirks theorem Fixed point theory and Appl., (2009),Article ID574387.

[14] Sarla Couhan and Neeraj Msalviya,A Fixed Point Theorem for Expancsive Type Mappiming in Cone Metric Spaces.International Mathematical Forum, 6, 18, (2011) 891-897. 